\title{
Association between airborne pollen and epidemic asthma in Madrid, Spain: a case-control study
}

\author{
Iñaki Galán, ${ }^{1}$ Alicia Prieto, ${ }^{2}$ María Rubio, ${ }^{2}$ Teresa Herrero, ${ }^{2}$ Patricia Cervigón, ${ }^{3}$ \\ Jose Luis Cantero, ${ }^{1}$ Maria Dolores Gurbindo, ${ }^{4}$ María Isabel Martínez, ${ }^{5}$ \\ Aurelio Tobías ${ }^{1,6}$
}

\begin{abstract}
${ }^{1}$ Department of Epidemiology, Consejería de Sanidad de la Comunidad de Madrid, Spain ${ }^{2}$ Department of Allergy, Hospital General Universitario Gregorio Marañón, Consejería de Sanidad de la Comunidad de Madrid, Madrid, Spain

${ }^{3}$ Department of Environmental Health, Consejería de Sanidad de la Comunidad de Madrid, Madrid, Spain

${ }^{4}$ Department of

Immunopediatrics, Hospital General Universitario Gregorio Marañón, Consejería de Sanidad de la Comunidad de Madrid, Madrid, Spain

${ }^{5}$ Department of Child Allergy, Hospital General Universitario Gregorio Marañón, Consejería de Sanidad de la Comunidad de Madrid, Madrid, Spain ${ }^{6}$ Institute of Environmental Assessment and Water Research (IDAEA), Spanish Council for Scientific Research (CSIC), Barcelona, Spain
\end{abstract}

\section{Correspondence to}

Iñaki Galán Labaca, Servicio de Epidemiología, Consejería de Sanidad, Comunidad de Madrid, C/ Julián Camarillo 4 B 28037 Madrid, Spain;

inaki.galan@salud.madrid.org

Received 5 May 2009 Accepted 13 February 2010

\begin{abstract}
Background Despite the fact that airborne pollen is an important factor in precipitating asthma attacks, its implication in increases of epidemic asthma in usual meteorological conditions has not been reported. A study was undertaken to estimate the relationship between various types of aeroallergens and seasonal epidemic asthma in the region of Madrid, Spain.

Methods A case-control study was carried out in individuals aged $4-79$ years who received emergency healthcare for asthma during 2001 in a base hospital covering a population of 750000 inhabitants of Madrid. A skin prick test was performed with grass pollen, plantain pollen, olive pollen, cypress pollen, plane tree pollen, dust mites and Alternaria and the prevalence of skin reactivity was compared between subjects with asthma requiring emergency care for asthma within (cases) and outside (controls) the seasonal epidemic period. Data were analysed using logistic regression adjusting for age and sex.
\end{abstract}

Results The response rate was $61.7 \%$ for cases $(n=95)$ and $51.6 \%$ for controls ( $n=146$ ). The OR of sensitisation to grass pollen for cases compared with controls was 9.9 (95\% Cl 4.5 to 21.5); plantain pollen: 4.5 (95\% Cl 2.5 to 8.2); olive pollen: 7.3 (95\% Cl 3.5 to 15.2$)$; plane tree pollen: 3.6 (95\% Cl 2.0 to 6.4); cypress pollen: 3.5 (95\% $\mathrm{Cl} 2.0$ to 6.2$)$; dust mites: 1.1 (95\% $\mathrm{Cl} 0.6$ to 1.9$)$; Alternaria: 0.9 (95\% Cl 0.5 to 1.9). The association with grasses was maintained after adjusting simultaneously for the remaining aeroallergens (OR $5.0(95 \% \mathrm{Cl} 1.5$ to 16.4)); this was the only one that retained statistical significance $(p=0.007)$.

Conclusions These results suggest that allergy to pollen, particularly grass pollen, is associated with the epidemic increase in asthma episodes during the months of May and June in the Madrid area of Spain.

\section{INTRODUCTION}

People with asthma are frequently more allergic than the general population and it is estimated that, in our environment, the population attributable risk of atopy in explaining asthma is $42 \%{ }^{1}$ Sensitisation to seasonal allergens in Spain, including grass pollen, is an independent risk factor for developing asthma. ${ }^{2}$

The region of Madrid has botanical and climatic characteristics which predispose to very high grass pollen concentrations. The continental climate, in which there is an abrupt temperature change during the months of April and May moving quickly from cold to hot days, favours the simultaneous flowering of most grass species. ${ }^{3}$ As a result, and depending on the meteorological conditions, ${ }^{4}$ very high concentrations of grass pollen are reached for 2-3 weeks between May and June, exceeding the threshold level above which most people sensitised to this pollen develop symptoms related to the disease. ${ }^{5} 6$ During this period and coinciding with the presence of high atmospheric pollen concentrations, an epidemic increase in asthma episodes or attacks is observed. ${ }^{7}$

Several studies based on time-series design have evaluated the short-term effects of aeroallergens on the healthcare demand for asthma exacerbations. Many have observed positive associations ${ }^{8-16}$ but others have found no relationship. ${ }^{17-19}$ In Madrid, a strong association between grass pollen and hospital emergency room admissions for asthma has also been shown. ${ }^{7}$

Apart for exceptional meteorological circumstances, such as thunderstorms in the presence of high grass pollen concentrations which have been associated with epidemic days of asthma, ${ }^{20}$ it has not been shown from individual observational studies that airborne pollen levels in usual meteorological conditions could cause epidemic asthma. ${ }^{21}$

The objective of this study was to estimate the association between various aeroallergens and seasonal epidemic asthma in the region of Madrid, comparing the prevalence of skin reactivity between subjects with asthma who require emergency healthcare for asthma within and outside the seasonal epidemic period.

\section{METHODS \\ Study design}

A case-control study was carried out in a population aged 4-79years who received emergency healthcare for asthma in the emergency room of the Hospital General Universitario Gregorio Marañón during 2001 ( $\mathrm{n}=900,359$ men and 541 women). This hospital is the reference hospital for a healthcare area of the region of Madrid and includes a population of 750000 inhabitants. Only the clinical diagnosis of asthma (ICD-9-CM diagnosis code 493) was considered, excluding terms such as bronchospasm, bronchial hyper-reactivity or asthmatic bronchitis.

People who received emergency healthcare for asthma during the epidemic period of May and June 2001 were defined as cases. The identification of epidemic days was based on those days of May and June which exceeded by three standard deviations the prediction made from a Poisson distribution for the time series between 1994 and 2001. ${ }^{22}$ Controls were defined as asthma episodes seen in 
emergency rooms on non-epidemic days. The selection of controls was undertaken in proportion to the number of clinical presentations for asthma in each of the months of 2001, stratified by age and sex to match the distribution among the cases. Figure 1 shows the daily emergency room visits for asthma during 2001 and the threshold (horizontal line) which defines the selection of cases and controls. A total of 154 cases and 283 controls were selected. We calculated that this population provided over $90 \%$ power at the $5 \%$ significance level to detect an OR of 4.0 assuming a $50 \%$ response rate and an exposure prevalence of $50 \%$ among controls. Exclusion criteria were the use of antihistamines in the previous 5 days and a negative histamine skin test.

A letter with information about the study was sent to the selected people to encourage their participation and at least six telephone call attempts were made in both groups to set up the appointment.

\section{Diagnostic procedures}

The skin prick test was performed from July to October 2002 by a previously trained allergist who was blinded to the allocation of participants as cases or controls. The reactivity to the following aeroallergens was measured: grass pollen (Phleum pratense L), plantain pollen (Plantago lanceolata L), olive pollen (Olea europaea L), cypress pollen (Cupressus arizonica E L Greene), plane tree pollen (Platanus x hispanica Mill. ex Muenchh), dust mites (Dermatophagoides pteronyissinus), fungi (Alternaria alternata (Fr) Keissler), and a histamine control was included using standardised allergenic extracts (ALK-Abelló, Hørsholm, Denmark). These tests were performed according to the methodology recommended by the Sub-Committee on Skin Tests of the European Academy of Allergology and Clinical Immunology. ${ }^{23}$ Positive results were considered as a weal $>3 \mathrm{~mm}$ in diameter. The correct performance of the allergy tests was evaluated in a pilot study with 30 volunteers in whom two prick tests were performed, comparing the measurement of the allergist in charge of the fieldwork with the measurement of another experienced allergist. The coefficient of variation between the two observers was less than $30 \%{ }^{24}$

\section{Statistical analysis}

Data were analysed using logistic regression to estimate the OR and its $95 \%$ CI for each of the allergens without the presence of

\section{Number of emergency room admissions}

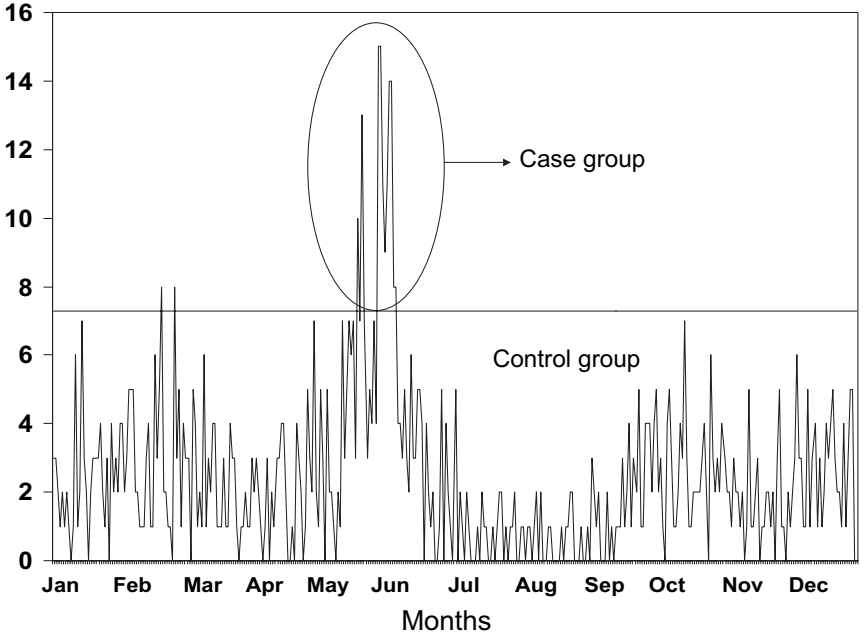

Figure 1 Daily emergency room visits for asthma in population aged $4-79$ years. Detection of epidemic days (cases) and non-epidemic days (controls). Region of Madrid, 2001. the others and also adjusting by the presence of all of them simultaneously. These models were also adjusted for age and sex. Analyses were done using Stata Version 10.0 (StataCorp, College Station, Texas, USA).

\section{RESULTS}

The response rate, measured as the number of complete interviews and skin prick tests divided by the number of complete plus incomplete plus non-conducted interviews (including negative interviews and no contacts), was $61.7 \%$ for the cases and $51.6 \%$ for the controls. No person was excluded from the study according to the criteria defined. The characteristics of the definitive sample did not differ statistically from the original. On the other hand, the comparability of cases and controls with respect to age and sex groups of the original sample selection was maintained (table 1)

Subjects who refused to participate in the study were requested to respond to a questionnaire by telephone to assess if they had a known allergy, performance of allergy tests and frequency of use of bronchodilators as an indirect indicator of asthma severity. Information about $42.4 \%$ of the cases and $23.4 \%$ of the controls who did not participate was obtained. No statistically significant differences were observed with respect to these variables.

Table 2 shows the prevalence of positive skin prick tests to the aeroallergens studied; $87.4 \%$ of the cases and $70.5 \%$ of the controls tested positive to one or more. In both cases and controls the main aeroallergens were grasses $(85.1 \%$ of cases and $47.6 \%$ of controls), olive ( $82.8 \%$ of cases and $49.0 \%$ of controls) and plantain $(70.0 \%$ of cases and $37.9 \%$ of controls).

Table 3 shows the polysensitisation to different allergens. Sensitisation to other types of pollen was more frequent in cases than in controls, with high prevalences of multiple sensitisation especially between plantain, grass and olive pollen. In both groups, the highest prevalence was observed with grass and olive pollen ( $81.5 \%$ of cases and $40.3 \%$ of controls), followed by reactivity to grasses and plantain pollen ( $68.5 \%$ of cases and $34.0 \%$ of controls). The combined prevalence of these three allergens was $66.7 \%$ and $31.5 \%$ in cases and controls, respectively (data not shown).

The OR of having a positive skin prick test to grasses, adjusted for age and sex, in the models with a single allergen was 9.9 in favour of the cases (95\% CI 4.5 to 21.5); 4.5 for plantain (95\% CI 2.5 to 8.2); 7.3 for olive (95\% CI 3.5 to 15.2 ); 3.6 for plane tree (95\% CI 2.0 to 6.4) and 3.5 for cypress (95\% CI 2.0 to 6.2). No association was observed for dust mites and Alternaria (table 4). The relationship with grasses was maintained after adjusting by the rest of the aeroallergens simultaneously (OR 5.0

Table 1 Demographic characteristics of study population

\begin{tabular}{|c|c|c|c|c|}
\hline & \multicolumn{2}{|l|}{ Cases } & \multicolumn{2}{|l|}{ Controls } \\
\hline & $\begin{array}{l}\text { Non- } \\
\text { participants } \\
(n=59)\end{array}$ & $\begin{array}{l}\text { Participants } \\
(\mathrm{n}=95)\end{array}$ & $\begin{array}{l}\text { Non- } \\
\text { participants } \\
(n=137)\end{array}$ & $\begin{array}{l}\text { Participants } \\
(\mathrm{n}=146)\end{array}$ \\
\hline \multicolumn{5}{|l|}{ Gender } \\
\hline Males & 49.2 & 47.4 & 49.6 & 50.0 \\
\hline Females & 50.8 & 52.6 & 50.4 & 50.0 \\
\hline$p$ Value ${ }^{*}$ & & 0.829 & & 0.951 \\
\hline \multicolumn{5}{|c|}{ Age groups (years) } \\
\hline $4-14$ & 40.7 & 42.1 & 40.1 & 45.9 \\
\hline $15-29$ & 27.1 & 27.4 & 27.7 & 23.3 \\
\hline $30-44$ & 22.0 & 17.9 & 21.9 & 21.2 \\
\hline $45-79$ & 10.2 & 12.6 & 10.2 & 9.6 \\
\hline p Value* & & 0.913 & & 0.769 \\
\hline
\end{tabular}

Data shown are percentages.

*Differences between participants and non-participants in the study. 
Table 2 Prevalence of positive skin prick test to various aeroallergens in cases and controls

\begin{tabular}{|c|c|c|c|c|}
\hline \multirow[b]{2}{*}{ Aeroallergens } & \multicolumn{2}{|l|}{ Cases } & \multicolumn{2}{|l|}{ Controls } \\
\hline & $\begin{array}{l}\text { Prevalence } \\
\text { (\%) }\end{array}$ & $95 \% \mathrm{Cl}$ & $\begin{array}{l}\text { Prevalence } \\
(\%)\end{array}$ & $95 \% \mathrm{Cl}$ \\
\hline Grasses & 85.1 & 76.3 to 91.6 & 47.6 & 39.2 to 56.0 \\
\hline Plantain & 70.0 & 59.4 to 79.2 & 37.9 & 30.0 to 46.4 \\
\hline Olive & 82.8 & 73.6 to 89.8 & 49.0 & 40.6 to 57.4 \\
\hline Cypress & 65.6 & 55.0 to 75.1 & 37.8 & 29.8 to 46.2 \\
\hline Plane tree & 53.7 & 43.2 to 64.0 & 26.6 & 19.5 to 34.6 \\
\hline Dust mites & 28.1 & 19.1 to 38.6 & 26.8 & 19.7 to 34.8 \\
\hline Alternaria & 15.1 & 8.5 to 24.0 & 16.9 & 11.1 to 24.1 \\
\hline $\begin{array}{l}\text { Any } \\
\text { aeroallergen }\end{array}$ & 87.4 & 79.0 to 93.3 & 70.5 & 62.4 to 77.8 \\
\hline
\end{tabular}

(95\% CI 1.5 to 16.4$)$ ), which was the only one to retain statistical significance $(p=0.007$, table 4). Figure 2 shows similar temporal distribution for plantain, grass and olive pollen.

\section{DISCUSSION}

To date, only epidemic increases in asthma associated with aeroallergens derived from soybean dust ${ }^{25} 26$ or with special meteorological conditions such as thunderstorms in the presence of grass pollen ${ }^{20}$ have been reported. The results of this study suggest that, in our geographical environment and in usual meteorological conditions, exposure to high pollen concentrations (mainly grass pollen) is related to epidemic-type asthma. The results of this individual-based study are consistent with previous time-series analyses conducted in the same geographical environment. ${ }^{7}$

As has been observed in the European Community Respiratory Health Survey (ECRHS), the sensitisation to allergens has a high geographical variability between countries and between participating centres within each country. After sensitisation to dust mites, grass pollen was the most frequent allergen in a group of 35 centres with an average prevalence of $18.9 \% .{ }^{27}$ The five Spanish cities participating in the ECRHS showed a low level of sensitisation to grass pollen, although most of these cities are in coastal areas where the conditions of exposure to grasses is very different from those of the centre of the peninsula, where it is considered the most important cause of pollinosis. ${ }^{3}$ The release of pollen into the environment occurs in a more regular manner in coastal areas and is distributed over several months. In the region of Madrid, however, $80 \%$ of the

Table 3 Prevalence of polysensitisation in cases and controls

\begin{tabular}{lllllll}
\hline & Plantain & Olive & Cypress & Plane tree & Dust mites & Alternaria \\
\hline Cases & & & & & & \\
Grasses & 68.5 & 81.5 & 35.2 & 52.1 & 28.4 & 14.1 \\
Plantain & - & 67.0 & 54.5 & 50.0 & 28.2 & 12.5 \\
Olive & & - & 64.8 & 54.8 & 26.1 & 14.3 \\
Cypress & & & - & 41.9 & 24.1 & 12.1 \\
Plane tree & & & & - & 22.5 & 9.7 \\
Dust mites & & & & & - & 9.4 \\
Controls & & & & & & \\
Grasses & 34.0 & 40.3 & 31.0 & 23.9 & 17.0 & 12.8 \\
Plantain & - & 33.3 & 26.8 & 22.5 & 15.6 & 12.1 \\
Olive & & - & 30.3 & 23.9 & 17.0 & 13.5 \\
Cypress & & & - & 18.6 & 11.4 & 11.4 \\
Plane tree & & & & - & 10.8 & 8.6 \\
Dust mites & & & & & - & 9.1 \\
\hline
\end{tabular}

Data shown are percentages.
Table 4 Association between having positive skin tests to various aeroallergens and demand from emergency rooms for asthma on epidemic days

\begin{tabular}{lllllll}
\hline Aeroallergens & $\mathbf{O R}^{*}$ & $\mathbf{9 5 \%} \mathbf{C l}$ & $\mathbf{p}$ Value & $\mathbf{O R} \dagger$ & $\mathbf{9 5 \%} \mathbf{C l}$ & $\mathbf{p}$ Value \\
\hline Grasses & 9.9 & 4.5 to 21.5 & $<0.001$ & 5.0 & 1.5 to 16.4 & 0.007 \\
Plantain & 4.5 & 2.5 to 8.2 & $<0.001$ & 1.3 & 0.5 to 3.2 & 0.638 \\
Olive & 7.3 & 3.5 to 15.2 & $<0.001$ & 2.1 & 0.7 to 6.1 & 0.164 \\
Cypress & 3.5 & 2.0 to 6.2 & $<0.001$ & 0.9 & 0.4 to 1.9 & 0.714 \\
Plane tree & 3.6 & 2.0 to 6.4 & $<0.001$ & 1.9 & 0.8 to 4.2 & 0.131 \\
Dust mites & 1.1 & 0.6 to 1.9 & 0.822 & 0.8 & 0.4 to 1.9 & 0.638 \\
Alternaria & 0.9 & 0.5 to 1.9 & 0.857 & 0.5 & 0.2 to 1.3 & 0.159 \\
\hline
\end{tabular}

*Odds ratio adjusted for age and sex.

†Odds ratio adjusted for age, sex and the rest of the aeroallergens.

total grass pollen occurs during the second half of May and the first half of June, reaching very high environmental concentrations in a short period. ${ }^{3}$ A larger burden of exposure to certain types of pollen can affect differences in the prevalence of sensitisation. For example, in the International Study of Asthma and Allergies in Childhood (ISAAC) in Spain in which children with a positive skin prick test to grasses in two very geographically different cities such as Cartagena (coastal area with low grass levels) and Madrid (centre of Spain with high grass concentrations) were compared, the prevalence of sensitisation to grass pollen was $3.0 \%$ and $25.5 \%$, respectively. ${ }^{28}$ This figure was doubled in wheezing children in Madrid. In another study conducted in our region, ${ }^{29} 57.3 \%$ of subjects with asthma were allergic to grasses, a figure very similar to the results observed for Madrid in the ISAAC study.

The mechanisms whereby grass pollen induces asthma are still not well known. Theoretically, the morphology of airborne pollen with a size of $15-55 \mu \mathrm{m}$ is too large to reach the lower respiratory pathways, ${ }^{30}$ so the allergens should be inhaled in the form of smaller particles. The existence of allergens in particles of a respirable size $(\leq 5 \mu \mathrm{m})^{30}$ has been known since the 1980s, although their origin is not completely clear. They probably reach the lower respiratory pathways by a combination of mechanisms including the physical breakdown of pollen in the environment; rupture of the pollen with cytoplasmic release of starch granules caused by rain; Ubisch bodies (small particles with a diameter of $0.02 \mu \mathrm{m}$ which can contain allergens); and formation of aerosols containing allergens which are bound and carried by ultrafine particles (eg, particles from the emission of diesel engines). ${ }^{31}$ Given the coincidence in time between the maximum grass pollen concentration and asthma in our region, it could be suggested that the time variability in the detection of intact pollen is also correlated with that of the allergen burden in the form of micronic particles. In spite of this, time shifts in this allergen burden have been observed in periods before and after the maximum pollination period which could be related to symptoms of pollinosis in susceptible people outside the seasonal period. ${ }^{32}$ Taking into account the fact that traditional pollen detection methods are based on the observation and quantification of the whole grain, the development of methods to measure the allergen burden could provide new evidence for the investigation of pollinosis in the future.

All the epidemic days considered for the selection of the cases match a grass concentration of $>30$ grains $/ \mathrm{m}^{3}$. Based on the panel study by Davies and Smith, ${ }^{33}$ it has been suggested that the number of grass grains necessary to trigger rhinitis or conjunctivitis symptoms in most patients is about 50 grains $/ \mathrm{m}^{3}$ on a daily average. Erbas et $a l^{15}$ observed that the maximum effect was reached with 30 grains $/ \mathrm{m}^{3}$. In the study conducted in 


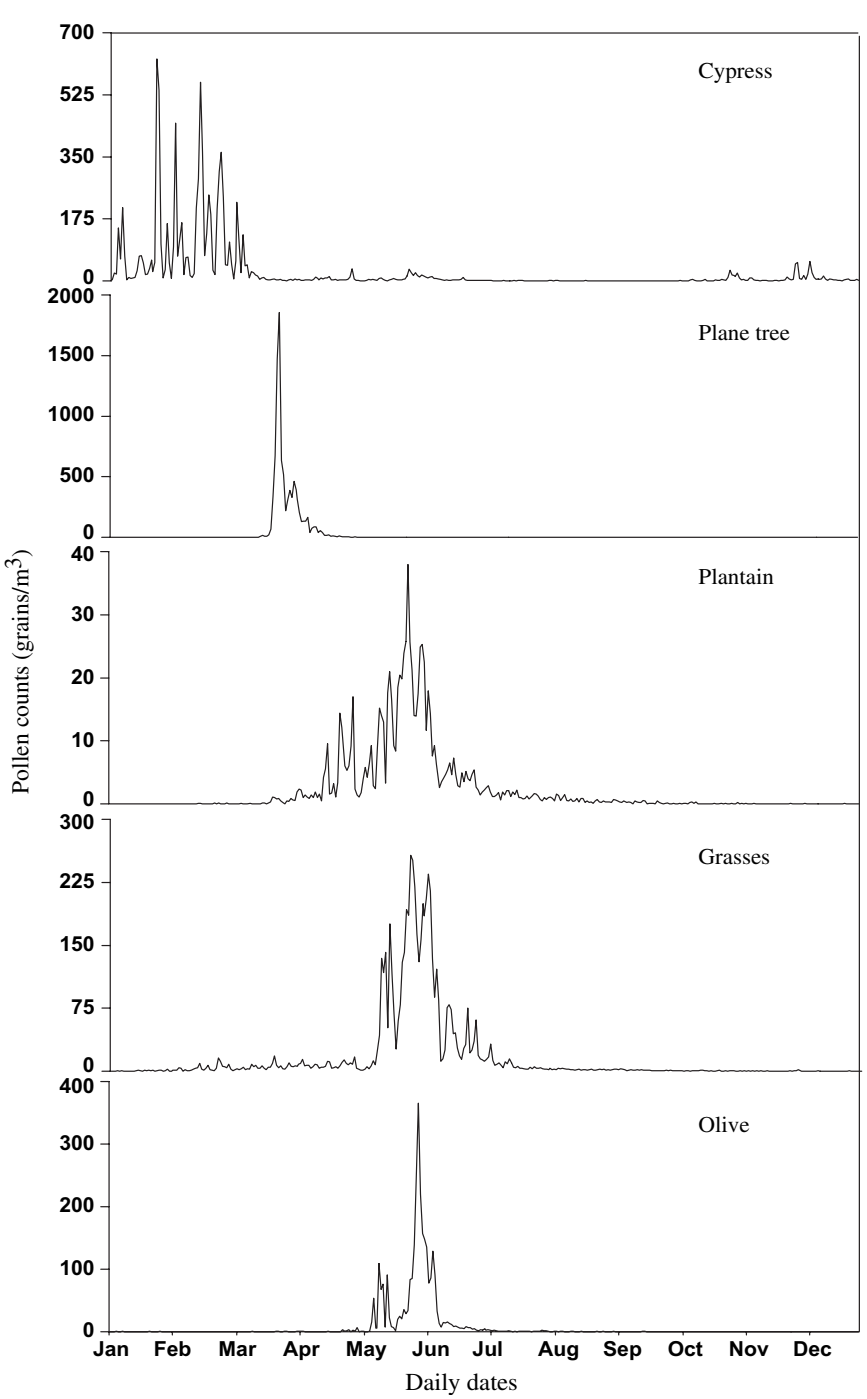

Figure 2 Seasonal distribution of pollen counts. Region of Madrid, 2001.

Madrid, Tobías et al reported a non-linear relationship between grass pollen and emergency room visits for asthma, finding an increase from $\geq 30$ grains $/ \mathrm{m}^{3}$. Unlike the previous study, however, a saturation level of the effect was not observed and the emergency room visits for asthma increased as the environmental grass pollen concentration increased. ${ }^{34} 35$

Another problem is isolating the independent effect of each pollen variety, taking into account the high prevalence of polysensitisation, especially between types of pollen that are also correlated in the atmosphere. ${ }^{7}$ The aggregation pattern observed in this study is similar to the one described by other authors in the Madrid area. ${ }^{36}$ In the case of cypress and plane tree pollen, although they are related to pollinosis, the symptoms are mainly seasonal rhinitis or conjunctivitis whereas grass, plantain and olive pollen are also associated with asthma exacerbations. ${ }^{3} 737$ Furthermore, unlike cypress pollen (January-February) and plane tree pollen (March-April), in Madrid these three types of pollen are released into the environment at similar times (May-June) which makes it more difficult to separate the effects, although plantain pollination is a couple of weeks before the start of grass pollination and olive pollination is slightly later. ${ }^{7}$ Although further studies are required to clarify this relationship, one hypothesis is that plantain pollen may cause an initial sensitisation at the start of the spring pollen season, causing a priming effect $^{5}$ in which the rapid release of grass pollen (with an environmental concentration that is $4-5$ times greater than that of plantain) would subsequently cause the epidemic precipitation of asthma attacks. Probably, as occurs in epidemic distributions, once the maximum exposure to the risk factor (in this case, grass pollen) has occurred, a 'depletion of susceptible people' would be reached and a considerable percentage of patients would be under medication control. This could prevent the development of new attacks to olive pollen, with an increase in environmental concentration that is slightly after grass pollen, in spite of the high degree of sensitisation observed.

Some limitations of the study should be considered. The response rate was not high, in spite of the fact that a study presentation letter was sent and numerous contact attempts were made. Nevertheless, the participation rate was similar to that of other studies in the area in which the performance of objective tests is required. Furthermore, a telephone survey was conducted with the people who did not participate in order to assess possible selection biases. However, despite not observing differences in the variables in allergy and use of bronchodilators, we cannot completely rule out the possibility of a response bias. On the other hand, the sample is representative of the entire demand made on emergency rooms during 1 year in a large reference hospital which covers a population forming $15 \%$ of the total of the region of Madrid. The definition of asthma used for the selection of cases and controls was very specific in order to minimise the number of false positives, discarding terms such as bronchospasm, bronchial hyper-reactivity or asthmatic bronchitis in clinical diagnoses. The skin prick test used has proved to be a good procedure for detecting IgE-mediated allergy diseases, it is widely used in epidemiological studies and it produces results comparable with other diagnostic techniques. ${ }^{38}$ Furthermore, the correct performance of the skin prick test was evaluated and the readings gave results comparable with those of another independent observer.

In conclusion, these results suggest that allergy to pollen-particularly grass pollen-is associated with an epidemic increase in asthma episodes during the months of May and June in the Madrid area of Spain. The prediction model of days with high pollen counts newly estimated by the pollen network of our region ${ }^{39}$ and the rapid dissemination of this information could help to prevent or reduce the exposure in susceptible people and, as a result, to minimise asthma exacerbations during the spring months.

\section{Competing interests None.}

Ethics approval This study was conducted with the approval of the bioethics committee of the Hospital General Universitario Gregorio Marañón.

Provenance and peer review Not commissioned; externally peer reviewed.

\section{REFERENCES}

1. Soriano JB, Anto JM, Sunyer J, et al. Risk of asthma in the general Spanish population attributable to specific immunoresponse. Spanish Group of the European Community Respiratory Health Survey. Int J Epidemiol 1999;28:728-34.

2. Sunyer J, Anto JM, Kogevinas M, et al. Risk factors for asthma in young adults. Spanish Group of the European Community Respiratory Health Survey. Eur Respir J 1997:10:2490-4.

3. Subiza J, Jerez M, Jimenez JA, et al. Allergenic pollen pollinosis in Madrid. J Allergy Clin Immunol 1995;96:15-23.

4. Subiza J, Masiello JM, Subiza JL, et al. Prediction of annual variations in atmospheric concentrations of grass pollen. A method based on meteorological factors and grain crop estimates. Clin Exp Allergy 1992;22:540-6.

5. Frenz DA. Interpreting atmospheric pollen counts for use in clinical allergy: allergic symptomology. Ann Allergy Asthma Immunol 2001;86:150-7.

6. Solomon WR. Aerobiology of pollinosis. J Allergy Clin Immunol 1984;74:449-61.

7. Tobias A, Galan I, Banegas JR, et al. Short term effects of airborne pollen concentrations on asthma epidemic. Thorax 2003;58:708-10. 
8. Anderson HR, Ponce de LA, Bland JM, et al. Air pollution, pollens, and daily admissions for asthma in London 1987-92. Thorax 1998;53:842-8.

9. Babin SM, Burkom HS, Holtry RS, et al. Pediatric patient asthma-related emergency department visits and admissions in Washington, DC, from 2001-2004, and associations with air quality, socio-economic status and age group. Environ Health 2007;6:9.

10. Dales RE, Cakmak $S$, Judek $S$, et al. Influence of outdoor aeroallergens on hospitalization for asthma in Canada. J Allergy Clin Immunol 2004;113:303-6.

11. Lewis SA, Corden JM, Forster GE, et al. Combined effects of aerobiological pollutants, chemical pollutants and meteorological conditions on asthma admissions and $A \& E$ attendances in Derbyshire UK, 1993-96. Clin Exp Allergy 2000;30:1724-32.

12. Lierl MB, Hornung RW. Relationship of outdoor air quality to pediatric asthma exacerbations. Ann Allergy Asthma Immunol 2003;90:28-33.

13. Rosas I, McCartney HA, Payne RW, et al. Analysis of the relationships between environmental factors (aeroallergens, air pollution, and weather) and asthma emergency admissions to a hospital in Mexico city. Allergy 1998;53:394-401.

14. Zhong W, Levin L, Reponen T, et al. Analysis of short-term influences of ambient aeroallergens on pediatric asthma hospital visits. Sci Total Environ 2006:370:330-6.

15. Erbas B, Chang $\mathrm{JH}$, Dharmage $\mathrm{S}$, et al. Do levels of airborne grass pollen influence asthma hospital admissions? Clin Exp Allergy 2007;37:1641-7.

16. Heguy L, Garneau M, Goldberg MS, et al. Associations between grass and weed pollen and emergency department visits for asthma among children in Montreal. Environ Res 2008;106:203-11.

17. Fauroux B, Sampil M, Quenel $P$, et al. Ozone: a trigger for hospital pediatric asthma emergency room visits. Pediatr Pulmonol 2000;30:41-6.

18. Garty BZ, Kosman E, Ganor E, et al. Emergency room visits of asthmatic children, relation to air pollution, weather, and airborne allergens. Ann Allergy Asthma Immunol 1998;81:563-70

19. Rossi OV, Kinnula VL, Tienari J, et al. Association of severe asthma attacks with weather, pollen, and air pollutants. Thorax 1993;48:244-8.

20. D'Amato G, Liccardi G, Frenguelli G. Thunderstorm-asthma and pollen allergy. Allergy 2007:62:11-6.

21. Strachan DP. The role of environmental factors in asthma. $\mathrm{Br}$ Med Bull 2000:56:865-82.

22. Hanslik T, Boelle PY, Flahault A. The control chart: an epidemiological tool for public health monitoring. Public Health 2001;115:277-81.

23. Haahtela T. Skin test used for epidemiologic studies. Allergy 1993;48(Suppl 14):76-80.

24. Chinn S. The assessment of methods of measurement. Stat Med 1990;9:351-62.
25. Antó J, Sunyer J, Rodriguez-Roisin R, et al. Community outbreaks of asthma associated with inhalation of soybean dust. Toxicoepidemiological committee. N Eng/ J Med 1989;320:1097-1102.

26. Hernando L, Navarro C, Marquez M, et al. Asthma epidemics and soybean in Cartagena (Spain). Lancet 1989;1:502

27. Bousquet PJ, Chinn S, Janson C, et al. Geographical variation in the prevalence of positive skin tests to environmental aeroallergens in the European Community Respiratory Health Survey I. Allergy 2007; 62:301-9.

28. Garcia-Marcos L, Garcia-Hernandez G, Morales Suarez-Varela M, et al. Asthma attributable to atopy: does it depend on the allergen supply? Pediatr Allergy Immunol 2007:18:181-7.

29. Galan I, Martinez M. Encuesta de Prevalencia de Asma de la Comunidad de Madrid. Documentos Tecnicos de Salud Publica N 20. Madrid: Consejeria de Salud, 1994.

30. Jaeger S. Exposure to grass pollen in Europe. Clin Exp Allergy Rev 2008;8:2-6.

31. Knox RB, Suphioglu C, Taylor P, et al. Major grass pollen allergen Lol $p 1$ binds to diesel exhaust particles: implications for asthma and air pollution. Clin Exp Allergy 1997:27:246-51.

32. Cabrera M, Martinez-Cocera C, Fernandez-Caldas E, et al. Trisetum paniceum (wild oats) pollen counts and aeroallergens in the ambient air of Madrid, Spain. Int Arch Allergy Immunol 2002:128:123-9.

33. Davies RR, Smith LP. Forecasting the start and severity of the hay fever season. Clin Allergy 1973;3:263-7.

34. Tobias A, Galan I, Banegas JR. Non-linear short-term effects of airborne pollen levels with allergenic capacity on asthma emergency room admissions in Madrid, Spain. Clin Exp Allergy 2004;34:871-8.

35. Tobias A, Saez M, Galan I, et al. Point-wise estimation of non-linear effects of airborne pollen levels on asthma emergency rooms admissions. Allergy. 2009.

36. Belver MT, Caballero MT, Contreras J, et al. Associations among pollen sensitizations from different botanical species in patients living in the northern area of Madrid. J Investig Allergol Clin Immunol 2007;17:157-9.

37. Liccardi G, D’Amato M, D'Amato G. Oleaceae pollinosis: a review. Int Arch Allergy Immunol 1996;111:210-17.

38. Tschopp JM, Sistek D, Schindler C, et al. Current allergic asthma and rhinitis: diagnostic efficiency of three commonly used atopic markers (IgE, skin prick tests, and Phadiatop). Results from 8329 randomized adults from the SAPALDIA Study. Swiss Study on air pollution and lung diseases in adults. Allergy 1998;53:608-13.

39. Red Palinológica de la Comunidad de Madrid. Consejería de Sanidad. http:// www.madrid.org/polen (accessed 20 Jan 2010). 